\title{
DISCLAIMER
}

This report was prepared 25 an tcoowat of work sponsored by an agency of the United Stalcs the United Sistes Covernment nor any agency thereof, nor any of their employen. Net implied, of assumes any legal liability of responsibibity for the accuracy, complettenese, or usefulness of any information, apparatus, product, of procese disckand, or represents tbat its use would nol iniringe privately awned rights. Reference berein to any specific commercial product, process, os service by trade name, trademart.

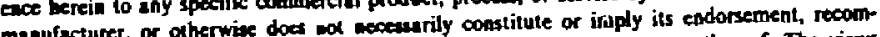
meadation, or fowories by the Uaited States Gowernment or any utency thereof. The views and orinions of authors expreaned bertin do not pecesurily late or reflect thowe of the Uniled Sules Gorersmeat or any apeacy ibereof.

\section{Solution of the Fokker-Planck Equa ion with Mixing of Angular Harmonics by Beam-Beam Charge Exchange}

\author{
D. R. Mikkelsen \\ PPPL--2653 \\ Princeton Plasma Physics Laboratory, \\ Princeton, NJ 08543, \\ LS.A
}

\begin{abstract}
A method for solving the linear Fokker-Planck equation with anisotropic beam-beam charge exchange loss is presented. The 2-D equation is transformed to a system of coupled 1-D equations which are solved iteratively as independent equations. Although isotropic approximations to the beambeam losses lead to inaccurate fast ion distributions, typically only a few angular harmonics are needed to include accurately the effect of the bearnbeam charge exchange loss on the usual integrals of the fast ion distribution. Consequently, the algorithm converges very rapidly and is much more efficient than a 2-D finite difference method. A convenient recursion formula for the compling coefficients is given and generalization of the method is discussed.
\end{abstract}




\section{Introduction}

Intense neutral beam heating of low density plasmas[1-4! can produce a charge exchange loss rate between the injected fast neutrals and the trapped fast ions that approaches the thermalization rate. The anisotropic velocity distributions of the beam neutrals and fast ions together with the strong energy dependence of thu charge exchange cross section produce a charge exchange loss rate with strong pitch angle dependence. When a Legendre expansion is used to represent the angular dependence of the distribution function, the normally independent 1-D equations for each Legendre harmonic $[6,7]$ are coupled by the anisotropic charge exchange loss.

In spite of this complexity a solution based on Legendre harmonics is preferable to a 2-D finite difference method because the fast ion particle density, current density, parallel and perpendicular pressures, beam-target and beam-beam fusion reactivities are integral quantities which involve only low order harmonics; the first three or four usually sufficel $7-9$. A finite difference algorithm with resp' ctable accuracy, on the other hand. requires many angular grid points and correspondingly mure calculation even if operator splitting is used to transform the 2-D problem to a pair of 1-I) problems. In addition, the most efficient method of calculating the beam-beam fusion reactivity is based on Legendre harmonics[9]; a distribution based on a difference grid needs to be converted to a Legendrs expansion to use it!

The general approach described in this paper can be more broadly applied $[5] ;$ any and all of the terms in the Fokker-Planck equation could have an angular dependence. A general nonlinear formulation [8] could be recast in this way. When the pitch angle domain is limited by loss cones, the basis functions are no longer Legendre polynomials and both the basis functions and the coupling coefficients must be determined numerically [8]. It is interesting to nute that only a few harmonics are needed for mirror machine simulations 8 . which are complementary to the example below in that they have near perpendiculas injection. loss cones, and anisotropic nonlinear Coulomb collision terms. 


\section{Coupled equations for the angular harmonics}

The usual approximate form (valid for $\exp \left(-\left(v / v_{\text {thi }}\right)^{2}\right) \ll 1$ and $\left(v / v_{\text {the }}\right)^{2} \ll$ 1) of the linear Fokker-Planck equation describing the fast ion velocity space distribution in background plasma is

$$
\begin{aligned}
\frac{\partial f}{\partial t}= & \frac{1}{\tau_{\mathrm{ec}} v^{2}} \frac{\partial}{\partial v}\left[\left(v^{3}+v_{\mathrm{c}}^{3}\right) f+\frac{1}{m_{\mathrm{b}} v}\left(v^{3} T_{\mathrm{c}}+v_{\mathrm{c}}^{3} T_{\mathrm{i}}\right) \frac{\partial f}{\partial v}\right] \\
& +\frac{v^{3}}{\tau_{\mathrm{p} e} v_{\mathrm{c}}^{3}} \frac{\partial}{\partial \zeta}\left(1-\gamma^{3}\right) \frac{\partial f}{\partial \zeta}-\nu_{\mathrm{cx}} f+S,
\end{aligned}
$$

where $\zeta=v_{\|} / v$ and $\tau_{\boldsymbol{w}}, v_{e}$, and $\tau_{\mathrm{pe}}$ are standard[10]. (Magnetic compression and electric field terms are neglected here.) The collision rates with Maxwellian background ions and electrons have ieen simplified by neglecting higher order corrections of order $\exp \left(-\left(v / v_{\mathrm{thi}}\right)^{2}\right)$ and $\left(\mathrm{v} / v_{\mathrm{the}}\right)^{2}$, respectively.

The charge exchange loss rate can be divided into two parts

$$
\nu_{c x}=\pi_{a}^{t h}<\langle\sigma v\rangle>_{c x}^{b c}+n_{0}^{b}<\langle\sigma v\rangle>_{c x}^{b b} .
$$

The 'beam thermal' losses arise from reactions with the more or le is jsutrupic thermal neutral gas arising from wall and volume sources: this te:m is not of specific interest here and is ignored below. The 'beam-beam' loss rate is anisotropic because the velocity space distribution of ne' trals in the injected beam is highly directional. In most circumstances there will be many beambeam terms; one for each of the three energy components in each of the ion sources in a neutral beam system.

The beam-beam reactivity for a ring of fast ions with velocity space position of $(v, \theta)$ reacting with a delta-function distribution of fast neutrals at $\left(r_{1, .}, \theta_{c}\right)$ is

$$
\langle\langle\sigma \nu\rangle\rangle_{\mathrm{cx}}^{\mathrm{bb}}=\frac{1}{\pi} \int_{0}^{\pi} v_{\mathrm{rel}} \sigma_{\mathrm{cx}}\left(v_{\mathrm{rrl}}\right) d \phi .
$$

where $v_{\text {rel }}^{2}=v^{2}+v_{0}^{2}-2 v v_{0}\left(\cos \theta \cos \theta_{0}-\sin \theta \sin \theta_{0} \cos \phi\right)$ and $\phi$ is the gyrophase angle relative to the component of the beam neutral velocity which is perpendicular to the magnetic field, $\cos \theta=\zeta$, and $\cos \theta_{0}=\zeta_{0}$.

For neutral and fast ion energies $\geq 30 \mathrm{keV} / \mathrm{amu}\langle\langle\sigma v\rangle\rangle_{\mathrm{c}}^{\mathrm{bb}}$ is a strong function of pitch angle (Fig. 1) because $\sigma_{c x}$ is a strong function of $v_{\text {rel }}[11]$. The greatest anisotropy occurs for unidirectional injection with $\left|\zeta_{\mathrm{o}}\right| \sim 1$ and 
$v \sim v_{0} ; \int(v, \zeta)$ is most anisotropic under the same conditions. For these reasons the test problem described below has parallel injection; the beambeam fusion reactivity provides a sensitive scalar measure of changes in the distribution function.

By expanding the distribution function and $\nu_{\mathrm{cx}}$ in Legendre polynomials

$$
\begin{aligned}
& f(v, \zeta)=\sum_{m=0}^{M} f_{m}(v) P_{m}(\zeta), \\
& \nu_{e x}(v, \zeta)=\sum_{n=0}^{N} \nu_{n}(v) P_{n}(\zeta),
\end{aligned}
$$

multiplying Eq. (1) by $P_{l}(\zeta)$, and integrating over $\zeta$, we obtain a coupled system of 1-D equations for the angular harmonics of the distribution:

$$
\begin{aligned}
\frac{\partial f_{l}}{\partial t}= & \frac{1}{\tau_{\mu} v^{2}} \frac{\partial}{\partial v^{\prime}}\left[\left(v^{3}+v_{c}^{3}\right) f_{l}+\frac{1}{m_{\mathrm{b}} v}\left(v^{3} T_{e}+v_{\mathrm{c}}^{3} T_{\mathrm{i}}\right) \frac{\partial f_{l}}{\partial v}\right] \\
& -\frac{l(l+1) v^{3}}{T_{p s} v_{c}^{3}} f_{l}-\sum_{m=0}^{M} \sum_{n=0}^{N} A_{l, m, n} f_{m} \nu_{n}+S_{l},
\end{aligned}
$$

for $l=0$ to $M$, where

$$
\begin{gathered}
S_{l}(v)=\frac{2 l+1}{2} \int_{-1}^{1} S(v, \zeta) P_{l}(\zeta) d \zeta, \\
A_{l, m, n}=\frac{2 l+1}{2} \int_{-1}^{1} P_{i} P_{m} P_{n} d x .
\end{gathered}
$$

The coupling coefficients, $A_{l, m, n}$ are zero if $l-m+n$ is odd or if the sum of any pair of indices is less than the remaining index. J. C. Adams $[13]$ derived a closed form expression for the coefficients:

$$
A_{l, m, n}=\frac{(2 l+1)(m+n-l) !(l-n-m) !(l+m-n) !}{(2 s+1) !(s-l) !^{12}(s-m) !^{2}(s-n) !^{2}},
$$

where $2 s=l+m+n$, but it may be more convenient to calculate them from the recursion relation

$$
A_{l, m, n}= \begin{cases}\delta_{l, m}, & \text { for } n=0 . \\ \left\{(m-1) \delta_{l, m+1}+m \delta_{l, m+1}\right] /(2 m+1), & \text { for } n=1, \\ \{(2 n-1)](m+1) \cdot A_{l, m+1, n-1}+m A_{l, m-1, n-1} ! /(2 m+1) & \\ \left.-(n-1) A_{l, m, n-2}\right\} / n, & \text { for } n>1,\end{cases}
$$


which follows from application of the identity

$$
P_{n}=\left[(2 n-1) x P_{n-1}-(n-1) P_{n-2}\right] / n
$$

to the definition of $A_{l, m, n}$.

The diagonal elements, $A_{l, l, n}$, are easy to handle; only the elements with $l \neq m$ couple what would otherwise be independent equations for each $f_{l}$. The coupling is less burdensome than it appears because many elements of $A_{i, m, n}$ are zero and in practice $N$ can be as small as 2 without serious loss of accuracy in the usual global properties of the fast ion distribution.

Ignoring the implicil dependence on $f l$ of the off-diagonal terms,

$$
\sum_{m \neq l}^{M} \sum_{n=0}^{N} A_{l, m, n} f_{m} \nu_{n},
$$

we may consider them to be pseudo source terms. When solving the equation for each $f_{t}$, the off-diagonal terms are evaluated using the most recent versions of the $f_{m}$ (which are initially zero). The iterative sulution of this set of 'independent' equations converges to the solution of the coupled set. Note that the coefficients of $f_{l}$ in Eq. (2) are unchanged during the iterations: thus the coefficients in the tridiagonal difference equations are set up unce and onlythe calculation of the 'source' and the elimination and back-substitution are iterated. This is a very convenient algorithm which usually converges very rapidly and involves only a modest change to existing codes.

The solution of an extreme situation is shown in Fig. 2. Even though the bearn-beam charge exchange loss is very large, the iterative method converges. The boundary conditions are standard: $f\left(v_{\mathrm{thi}}\right)=0$ (thermalization sink) and zero particle flux at $v_{\max }$. This example has $120 \mathrm{keV}$ neutral deuterium injection with $\zeta_{0}=0.95$ in a deuterium background plasma at a density of $n_{\mathrm{D}}=5 \times 10^{19} \mathrm{~m}^{-3}$, with temperatures of $10 \mathrm{keV}$, and $Z_{\mathrm{eff}}=1.0$. A deuterium 'beam' neutral density of $2 \times 10^{14} \mathrm{~m}^{-3}$ produces a deuterium source rate of $\bar{\tau} \times 10^{20} \mathrm{~m}^{-3} \mathrm{sec}^{-1}$. The source rate used in this test problem has been artificially reduced to insure that $n_{\text {fast }} \ll n_{\mathrm{e}}$ so that the different methods of handling the beam-beam charge exchange loss do not affect $n_{e}$ and, hence, the thermalization time scale. In this test problem $\tau_{\mathrm{se}}=1.5 \mathrm{sec}$. $E_{\mathrm{c}}=225 \mathrm{keV}, \tau_{\mathrm{ps}}=1.1 \mathrm{sec}$. and $\nu_{0.1 .2}^{-1}\left(v_{\mathrm{o}}\right)=(0.22,0.10,0.12)$ sec, respectively.

With such a large beann neutral density the beam-beam charge exchange loss has a dramatic effect on the steady-state fast ion distribution. The 
importance of the anisotropic part of the charge exchange loss is seen by comparing curve $c$ ), which corresponds to using only $\nu_{0}$, with curve e) where the full angular deperdence of $\nu_{\mathrm{cx}}$ is used. Both isotropic approximations - curves b) and c) - seriously underestimate the loss because the charge exchange reactivity has been averaged over pitch angle although most of the fast ions have a pitch as' gle near that of the neutrals.

The iterative procedure described above converged to a part in $10^{6}$ in 8 iterations. The fast ion particle density, pressure, and beam-beam fusion rate changed iess than $5 \%$ when $(M . N)$ were lowered from $(11,11)$ to $(7.3)$. When $\left|\zeta_{0}\right| \leq 0.8$, the accuracy is $5 \%$ or better with $(M, N)=(4,3)$ or greater.

\section{Discussion}

The a]gorithm described in the previous section has worked very well in simulations of 'supershots' in TFTH with convergence to the level of $10^{6}$ occurring in three or four iterations. The usual integrated properties of the distribution are typically changed by less than a percent when more than three harmonics are used to represent the charge exchange loss rate and the distribution. Beginning the iteration luop over the $f_{l}$ with $l-I I$ and working downward using the most recently calculated value of the $f_{m}$ converges slightly faster than starting with $l=0$ and working up in $l$. This occurs because the pitch angle scattering term in Eq. (2) grows as $l(l+1)$ and thus the high $l$ harmonics are less sensitive to the beam-beam charge exchange and are closer to their final values on the first pass than the low $l$ harmonics.

If many more harmonics are recquired, it is possible to use the technjques described by Karney[12] to vectorize more efficiently the elimination and back-substitution algorithm: the algorithm would also apparently be suitable for a parallel computer.

\section{Acknowledgment}

It is a pleasure to thank Charles Karney for helpful discussions and comments on the manuscript. This work was supported by I*.S. DoE Contract No. DE-AC02-76-CHO-3073. 


\section{References}

1' H. P. Eubank et al., PLT neutral beam heating results, in Plasma Physics and Controlled Nuclear Fusion Research (Proc. 7th Int. Conf., Innsbruck, 1978), page 167, Vienna, 1979. IA EA.

'2 J. D. Strachan et al., Phys. Rev. Lett. 58, 1004 (1987).

(3) JET team. JET latest results and future prospects, in Plasme Physics and Controlled Nuclear Fusion Research (Proc. 11th Int. Conf., Kyoto, 1986), page 31, Vienna, 1987, IAEA.

[4] N. Hosogane et al., Nucl. Fusion 28, 1781 (1988).

5] J. G. Cordey and W. G. F. Core, Phys. Fluids 17, 1626 (1974).

6] J. D. Callen, R. J. Colchin, R. H. Fowler. D. G. McAlees, and J. A. Rome, Neutral beam injection into tokamaks, in Plasma Physics and Controlled Nuclear Fusion Researth (Proc. 5th Int. Conf., Tohyo. 1974). page 645, Vienna, 1975. IAEA.

i7 J. Killeen, A. A. Mirin. and M. E. Kensink. The solution of the kinetic equations for a multispecies plasma, in Methods in (omputat'onal Physics, edited by B. Adler. S. Fernbach, and M. Rotenberg. volune 16. page 389, Academic Press. New York, 1976.

[8. J. G. Cordey, K. D. Marx. M. G. McCoy, A. A. Mirin, and M. E. Kensink, J. Comput. Phys. 28, $11 \ddot{3}$ (1978).

[9. M. N. Rosenbluth. W. M. MacDonald, and D. L. Judd, Phys. Rev. 107. ] $(195 \bar{i})$.

10 K. J. Goldston et al., J. Comput. Phỵs. 43. 61 (1981).

1]. A. (. Kiviere. Nuc]. Fusion 11. 363 (1971).

12. J. C. Adams, Prac. R Soc. London 27. 63 (1878).

13! C. F. F. Karney, Computer Physics Reports 4, 183 (1986). 


\section{Figure captions}

Figure 1 The beard-beam charge exchange reactivity, $\langle\langle\sigma v\rangle\rangle_{\mathrm{c}}^{\mathrm{bb}}\left(v_{\mathrm{o}}, \zeta\right)$, for $120 \mathrm{keV}$ deuterium neutrals and fast ions where $\left.\left.\zeta_{0}=\mathrm{a}\right) 1.0, \mathrm{~b}\right) 0.8, \mathrm{c}$ ) $0.6, \mathrm{~d}) 0$.

Figure 2 The lowest harmonic of the fast ion distribution function, $f_{0}(v)$, for several treatments of the beam-beam charge exchange loss applied to the model problem described in the text: a) no beam neutral density; b) the (isotropic) beam-target charge exchange reactivity, $\langle\langle\sigma v\rangle\rangle_{\mathrm{cx}}^{\mathrm{b}}$, for cold neutral gas is used in place of $\langle\langle\sigma v\rangle\rangle_{\mathrm{cx}}^{\mathrm{bb}}$. The first 11 harmonics of $f(v)$ together with 1,3 , and 11 harmonics of $\nu_{\alpha}$ are used for curves c), d), and e), respectively. 


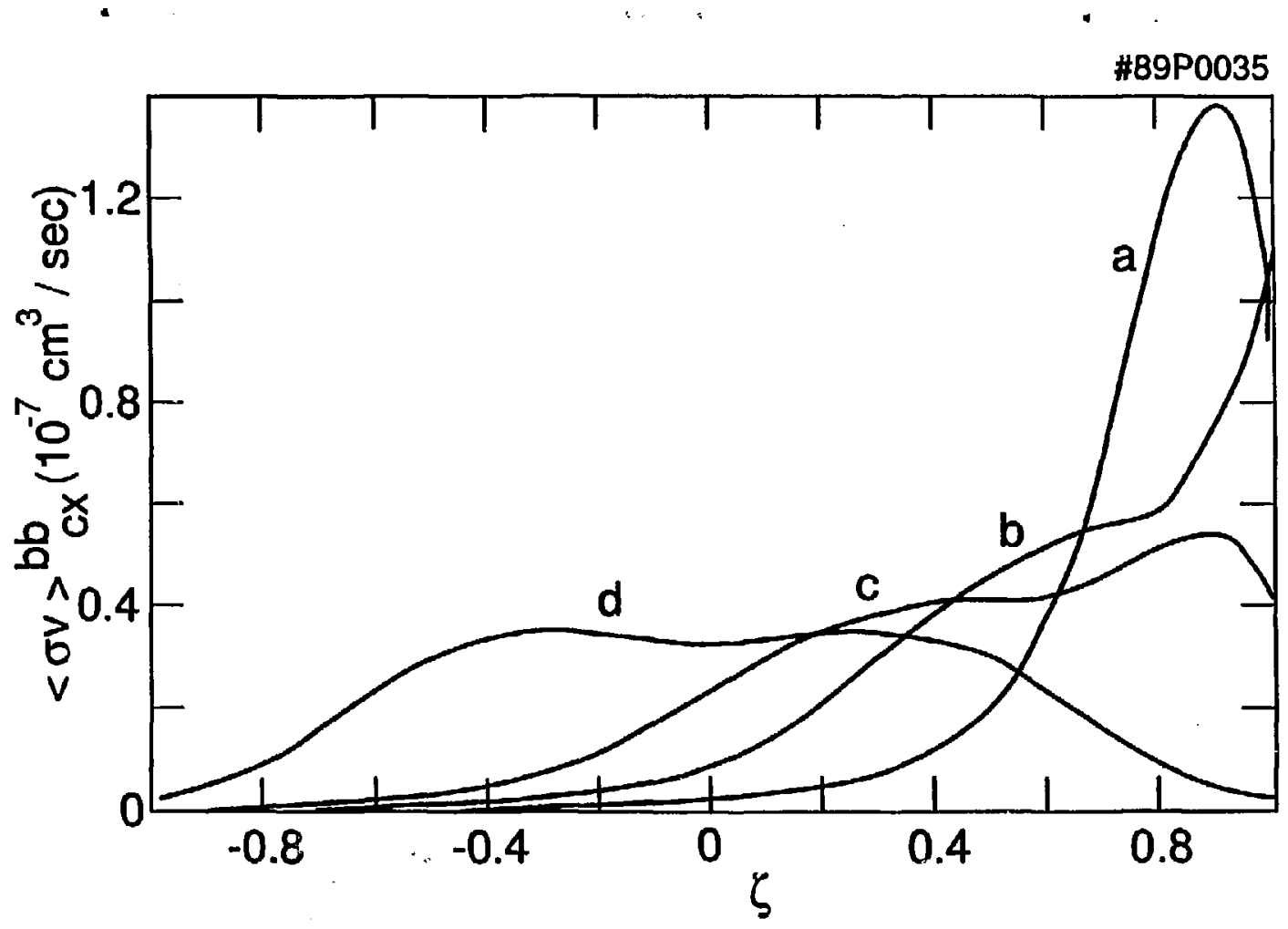

FIG. 1 
\#89P0034

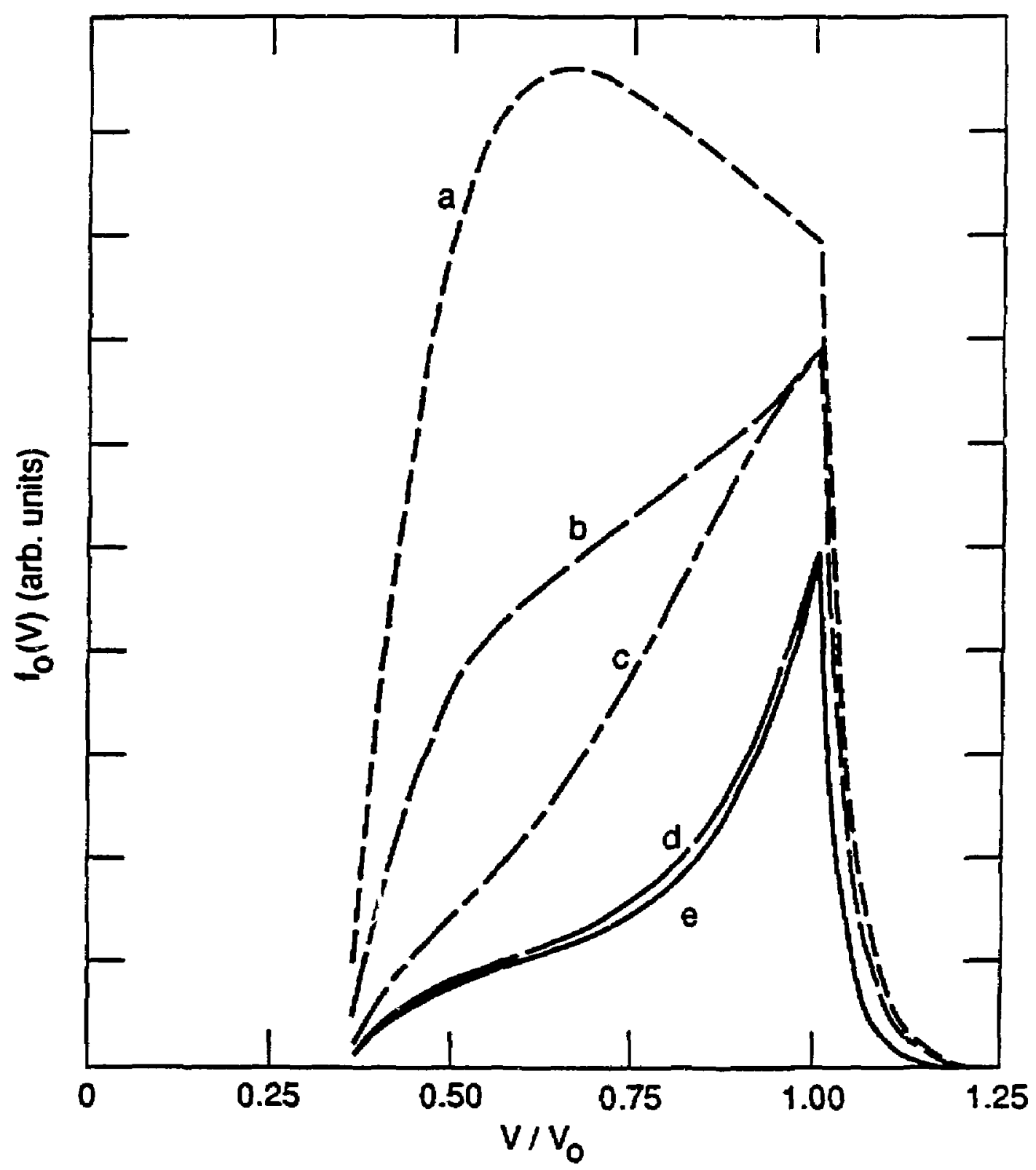

FIG 2 
Dr. Frank J. Pooloni, Univ of bol longong, ASSTRAL IA

Prol. M.H. Brennen, Umiv Syoney, Australia

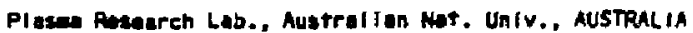

Prof. I.R. Jones, FIInders Univ., AUSTRALIR

Prof, F. Cep, Inst Theo Phys, Mustrik

Prof. M. Holnder, Instut fur Theoretische Ph: ४, MSSTRIA

M. Coossens, Astronoulech instituut, Belgive

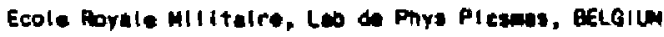

comisuion-European, Oo-XII fusion Prog. BELGILA

Prof. R. Boucique, Al jhsun iversitalt Cont, BeLGILN

Or. P.H. Sakenake, Instiruto figles, ERRIL

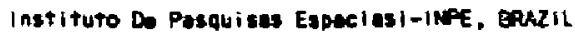

Docuents Office. Atcalic Enorgr of Canede Lieited, cawas

Dr. M.P. Eecnynsti, Mre Technologies, I re., cuman

Dr. H.M. Sharsgard, University of Sasketehewen, Caraba

Dr. H. Barnerd, University of Britikh Columbia, Cakna

Prof. J. Taichmann, Univ. of Montreal, cumon

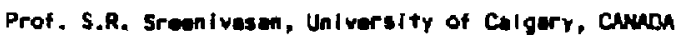

Prof. Tucor W. Johnstoa, Ifrs-Energle, cawoh

Or. Bolton, Cantre eanedien de fusion aegnétique, cawph

Or. C.R. Jeme, Univ, of hibertu, Cuwah

Dr. Poter Lukec, Komenakeho Univ, CZECHOSLOVAKiA

The Libretian, Culhe Leoratory, EkelaNo

The Librarian, Rutherford Appleton Letoratory, EkGLANo

wrs. S.A, Huteninson, JET Library, ERauld

c. Mouttat, Leo. an Pnysique des Milioun lonisós, fruce

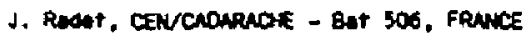

Hs. C. Rinni, Librarien, Univ. of lounnins, GREECE

Dr. To Mul, Acadery Bibllographle ser.. Howg kons

Preprint Library, Hungarian Acadery of Sciences, Hungary

Or. 9. Das Gupta, Sohe Inst of Huel. Phys., INDIA

Dr. P. Kaw, Institute for PI asase Rasearch, INOIA

Dr. Philid Rosenau, Isreel inst. of Tein, ISRaEL

Librarian, Int'i Ctr Theo Pnys, ITALY

Prot. G. Rostayni, Istituto Gas Ionizzati Dal OR, ITALY

Miss Clelis De Palo, Aasoc EURATCH-EMEA, I TALY

Dr. G. Grosso, Istituto di Fisica deI Plasaa, ITALY or. H. Yasto, Tokhibe Res a Dov, JAPAN
Prof. 1. Karakgmi. Atomic Energy Res. Instltute, JAPAN

Prot. Kyojl Mishikana, Univ of Hiroshlma, JAPAN

Diractor, Dapt, Large Tokanak Ras. JAERI, JAPAN

Prot. Satashi Itoh, Kiyushu University. JAPAN

Research Info Conter, Mogovo University, JAPAN

Prof. 3. Tanaka, Kroto Untversity, JAPAN

Library, Kyoto Univarsity, JAPN

Prof. Hobuyuki Innue, University at Tokyo, JAPAN

5. Mor $i$, JAER1, JAPAK

H. Jeong, LIbrarian, Korea Advanced Energy Ras Inst, KOREA Prot. D.1. Chol, The Korea Adv, Inst of Sci \& Tech, KOKëA Prot. B.s. Liley, University of Walkato, NEW ZEALANO Institute of PIasmo Physies, PEOPLE'S REPUBLIC OF CHINA Librarlen, Institute of Phys., PECPLE'S REPU⿴囗IC OF CHIMA Library, Tsing the Univarsity, PEOPLE'S REPUBLIC OF JHIMA z. Li, Southwest Inst. Physics, PEOPLE's REPU⿴囗IC OF CMINA Prof. J.A.C. Cabral, Inst Suparior Tecnico, PoRTLGAL Or. Octavian Petrus, AL I CUZA Univarsity, Romula D. Ja de villiers, Fusion studies, AEC, SO AFRICa Prot. M.A. Hellberg, Urivarsity of Hatal, SO AFr!CA C.I.E.M.A.T., Fusion Div. Library, SPAIN Or. Lennart Stent lo, University of IMEA, SHEDEN Library, Royel Instilute of Teeh, SWEDEN Prot. Hans Withelatson, Chalmers Univ of rech, WEDEN Contre Phys ons Plasmas, Ecole Polytoch red, SWITZERLAND Bibliotheek, Fom-Inst Yoor Plasna-fysica, the NeTHERLNOS . Motin Ourgut, Midde East Teennical Univargity, TUPKEY Dr. O.D. Ryutov, Sigerian Acad SEi, USSR

Dr. G.A. Eliseve. Kurchator Institute, USSR

Or. V.A. Glukhikh, Inst Electrophysleal Apparatus, USSR Prof. 0.5. Patichanko, Inst, of Phys. 8 Tech. USSR Or. L.M. Kovrizhnykh, Institute of Gan. Fhysies, USSR Huclear Aas. Establistuent, Juilich Ltd., W. GEPuWY Blbliothok, lost. Fur Plasmaforschung, W. Gefanwy J. K. Sehindior, Ruhr-Universitat Bochun, W. GERAAHY ASDEX Rasing Ro, c/o Wagner, IPP/Aax-PIanch, H, GERMANY Librarian, Maxplanek Institlt, W. GERMANY Prof. R.K. Jonev, Inst of Phys, YugOSLAVIA 


\title{
NOTICE
}

\author{
Available from: \\ National Technical Information Service \\ U.S. Department of Commerce \\ 5285 Port Royal Road \\ Springfield, Virginia 22161 \\ 703-487-4650
}

Use the following price codes when ordering:

Price: Printed Copy $\mathrm{A03}$

Microfiche A01 